\title{
The CREB/CREM Transcription Factors Negatively Regulate Early Synaptogenesis and Spontaneous Network Activity
}

\author{
Fernando Aguado, ${ }^{1 *}$ Carmen Díaz-Ruiz, ${ }^{1 *}$ Rosanna Parlato, ${ }^{2 *}$ Albert Martínez, ${ }^{1}$ Maria A. Carmona, ${ }^{1}$ \\ Susanne Bleckmann, ${ }^{2}$ Jesús M. Ureña, ${ }^{1}$ Ferran Burgaya, ${ }^{1}$ Jose A. del Río, ${ }^{1}$ Günther Schütz, ${ }^{2}$ and Eduardo Soriano ${ }^{1}$ \\ ${ }^{1}$ Institute for Research in Biomedicine, Department of Cell Biology, and Centro de Investigación Biomédica en Red para Enfermedades Neurodegenerativas, \\ Instituto de Salud Carlos III, University of Barcelona, 08028 Barcelona, Spain, and ²Molecular Biology of the Cell I, German Cancer Research Center, 69120 \\ Heidelberg, Germany
}

The family of CREB (cAMP response element-binding protein) transcription factors are involved in a variety of biological processes including the development and plasticity of the nervous system. In the maturing and adult brain, CREB genes are required for activitydependent processes, including synaptogenesis, refinement of connections and long-term potentiation. Here, we use

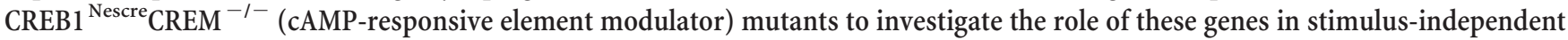
patterns of neural activity at early stages. We show that lack of CREB/CREM genes specifically in neural tissue leads to increased synaptogenesis and to a dramatic increase in the levels of spontaneous network activity at embryonic stages. Thus, the functions of CREB/CREM genes in neural activity differ in distinct periods of neural development.

Key words: CREB/CREM; development; hippocampus; mouse; network activity; synaptogenesis

\section{Introduction}

Activity-dependent neural plasticity is a crucial event during the postnatal critical period and in the adult brain. Stimulusdependent activity is required for the refinement of connections, formation and stabilization of synapses, and plasticity processes such as long-term potentiation (LTP) (Katz and Shatz, 1996; Hensch, 2005). The transcription factors of the CREB (cAMP response element-binding protein) family are key mediators of stimulus-induced nuclear responses that underlie activitydependent processes, including synaptogenesis, refinement of neural connections, and LTP (Murphy and Segal, 1997; Gass et al., 1998; Mayr and Montminy, 2001; Barco et al., 2002; Lonze et al., 2002; Pittenger et al., 2002; Gao et al., 2004; Marie et al., 2005). In addition to stimulus-regulated neural activity during the critical period, developing neurons pass through an earlier period of patterned neural activity, known as the "precritical period," which is stimulus independent (Feller and Scanziani, 2005). Such early patterns of neural activity are characterized by the recruitment of large numbers of neurons into synchronous waves (Ben-

\footnotetext{
Received 0ct. 31, 2008; accepted Nov. 14, 2008.

This work was supported by Spanish Ministry of Education and Science Grants BFU2006-13651 (J.A.d.R.), BFU2004-01154 and BFU2007-67889 (F.A.), and SAF2005-0171 (E.S.); Bundesministerium für Bildung und Forschung through German-Polish Cooperation project $01 \mathrm{GZ} 0310$ and Nationales Genomforschungsnetz Grant KGCV1/ 01GS0416; and grants from the Instituto de Salud Carlos III (Centro de Investigación Biomédica en Red para Enfermedades Neurodegenerativas (B06/05/0098 and PI04-2280). We thank Stefanie Stotz and Susana Maqueda for technical support, the researchers mentioned in the text for having shared reagents, and Tanya Yates for editorial assistance.

${ }^{*}$ F.A., C.D.-R., and R.P. contributed equally to this work.

Correspondence should be addressed to Dr. Eduardo Soriano, Institute for Research in Biomedicine, Barcelona Science Park, Lab A1-S1, University of Barcelona, Baldiri Reixac 10, 08028 Barcelona, Spain. E-mail: eduardo.soriano@irbbarcelona.org.

DOI:10.1523/JNEUROSCI.5252-08.2009

Copyright $\odot 2009$ Society for Neuroscience $\quad$ 0270-6474/09/290328-06\$15.00/0
}

Ari, 2001). The pattern of activity of these synchronous waves has been proposed to regulate processes such as gene expression and neuronal differentiation and gross map patterning and refinement (Stellwagen and Shatz, 2002; Torborg et al., 2005; Hooks and Chen, 2006; Huberman et al., 2006; Spitzer, 2006). Here, we show that lack of CREB/CREM (cAMP-responsive element modulator) genes specifically in neural tissue is not required for the formation of axonal tracts in vivo in the mouse embryo. Unexpectedly, we found that the lack of these transcription factors increases cortical synaptogenesis and dramatically increases the levels of spontaneous neural activity at early stages, indicating that the CREB/CREM genes play opposing roles in neural activity which are developmentally regulated.

\section{Materials and Methods}

Animals. The generation of the $\mathrm{CREB}^{\mathrm{Nescre}} \mathrm{CREM}^{+/-}$and CREB1 ${ }^{\text {Nescre }} \mathrm{CREM}^{-1-}$ mutants as well as the procedures to determine the genotype by PCR have been reported previously (Mantamadiotis et al., 2002).

Histology. Embryos were transcardially perfused at embryonic day 18 (E18) with 4\% paraformaldehyde, and brains were postfixed, cryoprotected, and frozen in dry ice. Coronal sections ( $40 \mu \mathrm{m}$ thick) were Nisslstained or immunostained with the anti-TAG-1, and anti-L1 (1:1000; a gift from J. Rathjen, Medical Research Council, Berlin, Germany) antibodies. After incubation with biotinylated secondary antibodies, sections were processed using the Vectastain ABC kit (Vector Laboratories).

Protein brain extracts and Western blot. The brains of control and mutant mice were collected at E18 and homogenized in Tris $50 \mathrm{~mm}, \mathrm{pH} 7.4$, $150 \mathrm{~mm} \mathrm{NaCl}, 1 \%$ Triton X-100, 2 mm EDTA, 10\% glycerol, 1 mm aprotinin, $1 \mathrm{~mm}$ leupeptin, $0.2 \mathrm{~mm}$ PMSF, $0.1 \mathrm{M} \mathrm{NaF}, 10 \mathrm{~mm}$ sodium pyrophosphate, and $0.2 \mathrm{~mm}$ sodium orthovanadate. After centrifugation, supernatants were analyzed by Western blot. Protein samples were separated by SDS-PAGE at $150 \mathrm{~V}$. After running, transfer to nitrocellulose membranes was performed in $120 \mathrm{~mm}$ glycine, $125 \mathrm{~mm}$ Tris, and 
$0.1 \%$ SDS and 20\% methanol. Filters were then saturated in 3\% BSA in TBS and incubated with the following antibodies: anti-GABA ${ }_{\mathrm{A} \alpha 1}$, antiGlu2/3 (1:1000; Millipore), and NMDA receptor subunit NR1 (1:1000; a gift from M. Watanabe, Hokkaido University School of Medicine, Sapporo, Japan). Anti- $\beta$-tubulin (1:10,000; Roche Diagnostics) and antiactin (1:50,000; Millipore) were used as loading controls. Secondary antibodies were used at 1:2000 in TBS-T containing 3\% powder milk. Labeling was visualized using ECL plus (GE Healthcare). All the Western blot data represent a minimum of three separate experiments. For densitometric analyses, the Quantity One (Bio-Rad) program was used.

Electron microscopy. E18 embryos [CREB1 ${ }^{\text {Nescre }}$ CREM $^{-1-}(n=3)$, $\mathrm{CREB}{ }^{\text {Nescre }} \mathrm{CREM}^{+/-}(n=2), \mathrm{CREB}^{+/+} \mathrm{CREM}^{-/-}(n=2)$ and $\left.\mathrm{CREB}^{+/+}{ }^{+/} \mathrm{CREM}^{+/-}(n=3)\right]$ were processed for electron microscopy. Briefly, mice were perfused with $2 \%$ glutaraldehyde- $2 \%$ paraformaldehyde in $0.1 \mathrm{~m}$ phosphate buffer. Brains were removed from skulls and fixed overnight in the same fixative solution. Fixed brains were sectioned and postfixed with $2 \%$ osmium tetroxide, dehydrated, and embedded in Araldite. Ultrathin sections were collected, stained with uranyl acetate and lead citrate, analyzed and photographed. Serial adjacent electron micrographs, each covering $64 \mu \mathrm{m}$ (final magnification 20,000×; $n=$ 45-64 per group of mice), were obtained from the stratum radiatum and the stratum lacunosum-moleculare of the hippocampus. The density axon terminals that displayed at least one synaptic contact were analyzed in double and single mutants and in their control littermates. In addition, we analyzed the surface area of randomly selected synaptic terminals ( $n=45-55$ per group) and dendrites $(n=40-70$ per group of animals) with the aid of the IMAT image analysis program (Scientific-Technical Services, University de Barcelona, Barcelona, Spain). Statistical analyses were performed using the Student's $t$ test.

$\mathrm{Ca}^{2+}$ imaging. Neuronal activity was recorded on hippocampal acute slices from E18 control and single- and double-mutant embryos (Schwartz et al., 1998; Aguado et al., 2003). The brains were removed and placed in cold artificial CSF (ACSF), bubbled with $95 \% \mathrm{O}_{2}$ and $5 \% \mathrm{CO}_{2}$. Transversal hippocampal slices ( $300 \mu \mathrm{m}$ thick) were obtained by cutting tissue pieces in a Mcllwain tissue chopper (Mickle Laboratory) and kept in a storage chamber containing oxygenated ACSF. $\left[\mathrm{Ca}^{2+}\right]_{\mathrm{i}}$ in slices was measured with the membrane-permeant acetoxymethyl ester of fura-2, fura-2-AM (Invitrogen) dissolved in DMSO with $0.001 \%$ pluronic acid (Invitrogen). Images were captured in an upright fluorescence microscope (BX50WI; Olympus) at room temperature $\left(22-25^{\circ} \mathrm{C}\right)$ with a silicon-intensifier tube camera (Hamamatsu; C2400-08). Fura-2 fluorescence images were collected at $4 \mathrm{~s}$ intervals (average of 15 frames for each time point) using a $380-\mathrm{nm}$ bandpass filter controlled by the National Institutes of Health Image program. ( \pm )-2-amino-5phosphonopentanoic acid (APV), 6-cyano-7-nitroquinoxaline-2, 3-dione (CNQX) (-)-bicuculline methiodide (BMI), and EGTA were obtained from Sigma and thapsigargin from CalbiochemNovabiochem.

Network analysis. Changes in fluorescence, $\Delta F / F=\left(F_{0}-F_{1}\right) /\left(F_{0}\right)$, were analyzed with a program written in Interactive Data Language (Research Systems) (Schwartz et al., 1998; Aguado et al., 2003). The time of initiation of each $\mathrm{Ca}^{2+}$ transient for each cell was marked on a raster plot. These plots were used to calculate the matrix of asymmetric correlation coefficients between all cell pairs. Contingency tables and $\chi^{2}$ tests were then used to detect the correlation coefficients that were significantly greater than expected. Significant correlation coefficients were used to generate a correlation map in which lines link neurons whose asymmetric correlation coefficient is significant $(p<0.01)$ and in which the thickness of a line connecting any two cells represents the magnitude of the greatest asymmetric correlation coefficient between the cells. To test whether the $\left[\mathrm{Ca}^{2+}\right]_{\mathrm{i}}$ transients showed associations between the neurons within a network, the number of simultaneous activations in a recording was calculated and used as a statistical test (Schwartz et al., 1998; Aguado et al., 2003). To determine its $p$ value, the distribution of the statistics under the null hypothesis of independent transients was computed by Monte Carlo simulation. The $p$ value was then estimated as the proportion of the 1000 replications in which the statistical test exceeded the statistical test computed from the true data. To simulate independent realizations of the transients, the number of cells, activations and time intervals were preserved, but the initiations of the transients were taken at random. Statistical analyses were performed using the Student's $t$ and Mann-Whitney $U$ tests. Data are expressed as mean \pm SEM.

\section{Results \\ Increased synaptogenesis in the hippocampus of CREB $1{ }^{\text {Nescre }}$ CREM $^{-/-}$embryos}

To specifically investigate the role of the CREB family of transcription factors on early neural activity in vivo, we generated mouse embryos lacking CREB specifically in glial and neural progenitors, in addition to the lack of one or two CREM alleles (Mantamadiotis et al., 2002). CREB1 ${ }^{\text {Nescre }} \mathrm{CREM}^{-1-}$ mice die at birth, and thus we analyzed them at E18. We first addressed whether the CREB/CREM family of transcription factors are required for axonal growth and the development of neural connections in vivo. Brain sections were immunostained for the axonal markers L1 and TAG-1, two adhesion molecules that are enriched in developing axonal tracts. We did not observe differences in the trajectories or in the thickness of axonal tracts between the various genotypes (Fig. $1 A-H$ ). Thus, the major commissures of the forebrain, including the corpus callosum, and the hippocampal and anterior commissures, were well developed in CREB $1{ }^{\text {Nescre }}$ CREM $^{-1-}$ mutant brains (Fig. $1 A, B$ ). Similarly, the distribution of axonal fascicles in several forebrain regions, including the intermediate zone of the neocortex, the alveus and fimbria in the hippocampus, or the reciprocal thalamocortical bundles that traverse the striatum, was indistinguishable in control and CREB ${ }^{\text {Nescre }} \mathrm{CREM}^{-/-}$mutant brains (Fig. $1 C-H$ ). Similar findings were observed in other brain areas such as the cerebellum and the brainstem (data not shown). We conclude that the CREB/CREM genes are not required for early axonal growth and guidance in vivo.

In the adult brain, the CREB family of transcription factors is involved in synaptic plasticity and synaptogenesis (Lonze et al., 2002; Gao et al., 2004). Therefore, we reasoned that although the lack of CREB/CREM genes does not alter axonal guidance, it may affect synaptogenesis once axons have reached their targets. We performed an electron microscopy study in the hippocampus at E18. At this age, immature synaptic terminals containing few synaptic vesicles were recognizable in the plexiform layers of the hippocampus (Aguado et al., 2003). Often, these terminals established synaptic contacts with adjacent profiles corresponding to dendrites. No difference was observed in the fine structure of synaptic terminals, dendrites or synaptic contacts between the genotypes studied, including control and CREB $1{ }^{\text {Nescre }} \mathrm{CREM}^{-1-}$ littermate embryos (Fig. 1I,J). We also measured the surface area of synaptic terminals and dendrites, which did not differ between control and CREB ${ }^{\text {Nescre }}$ CREM $^{-/-}$mutant embryos $(0.47 \pm$ $0.06 \mu \mathrm{m}^{2}$ and $0.36 \pm 0.04 \mu \mathrm{m}^{2}$ in synaptic terminals and $0.75 \pm$ $0.11 \mu \mathrm{m}^{2}$ and $0.96 \pm 0.16 \mu \mathrm{m}^{2}$ in dendrites of control and $\mathrm{mu}-$ tant hippocampi, respectively). Interestingly, the density of synaptic contacts in the hippocampus of CREB ${ }^{\text {Nescre }}{ }^{\mathrm{CREM}}{ }^{-1-}$ embryos was greater than in control littermates (Fig. $1 \mathrm{~K}$ ). This was particularly noticeable in the stratum lacunosum-moleculare (49\% increase), which receives entorhinal input and matures earlier than the stratum radiatum. The density of synaptic contacts (15-35\%) was also greater in embryos lacking only the CREB $\left(\mathrm{CREB}{ }^{\text {Nescre }} \mathrm{CREM}^{+/-}\right)$or the CREM $\left(\mathrm{CREB} 1^{+/+} \mathrm{CREM}^{-1-}\right.$ ) gene, indicating that both transcription factors are required to ensure the correct complement of synapses at early stages of corticogenesis. These data indicate that the lack of CREB and CREM genes does not impair axonal growth or synapse formation in vivo but results in increased synaptogenesis in the embryonic brain. 


\section{Increased levels of spontaneous activity in hippocampus of CREB $1^{\text {Nescre }}$ CREM $^{-/-}$embryos}

At perinatal stages, the hippocampus and other brain regions display patterns of intrinsic spontaneous neural activity, which are essentially synaptically driven (Garaschuk et al., 1998, 2000; Ben-Ari, 2001). We thus examined whether the increased synaptogenesis in CREB1 ${ }^{\text {Nescre }} \mathrm{CREM}^{-/-}$ mutants alters neural activity levels. To study the impact of CREB and CREM deletions on the activity of developing circuits, we analyzed spontaneous $\left[\mathrm{Ca}^{+2}\right]_{\mathrm{i}}$ changes in hippocampal slices of several mutant embryos by $\mathrm{Ca}^{+2}$ imaging (Schwartz et al., 1998; Aguado et al., 2003). After loading the dye fura-2, many neurons were stained throughout the principal and plexiform layers of the hippocampus (Fig. 2A,B). Analyses of E18 hippocampal neurons from control CREB $1 ~^{+/+}$CREM $^{+/-}$embryos showed that $\sim 10 \%$ of fura-2-loaded neurons exhibited spontaneous $\left[\mathrm{Ca}^{+2}\right]_{\mathrm{i}}$ oscillations, with a mean frequency of activation of $19.7 \pm 1.8\left[\mathrm{Ca}^{+2}\right]_{\mathrm{i}}$ transients $/$ cell $/ 10^{4} \mathrm{~s}(13$ slices from 5 embryos) (Fig. 2C, $H, I$ ). These low levels of spontaneous activity are consistent with the weak intrinsic activity reported in prenatal mouse hippocampi (Aguado et al., 2003). CREB $1{ }^{\text {Nescre }}$ CREM $^{-/-}$embryos (eight slices from four embryos) had more spontaneously active neurons and a higher frequency of spontaneous $\left[\mathrm{Ca}^{2+}\right]_{\mathrm{i}}$ oscillations than control CREB $1^{+/+} \mathrm{CREM}^{+/-}$ embryos (Fig. 2C, H,I). Moreover, in mutant embryos lacking either the CREB or the CREM gene, there was a nonsignificant increase in the number of active neurons (six to eight slices from three embryos per each genotype) and a significant $51.9 \%$ increase in the frequency of spontaneous $\left[\mathrm{Ca}^{2+}\right]_{\mathrm{i}}$ oscillations (Fig. 2H,I). No changes were detected in the duration of $\left[\mathrm{Ca}^{2+}\right]_{\mathrm{i}}$ transients in any of the genotypes analyzed (Fig. $2 J$ ).

Synchronous activation of developing neurons is believed to be a crucial step in the development of neural circuits (Katz and Shatz, 1996; Ben-Ari, 2001). We analyzed the effect of CREB and CREM mutations on the patterns of synchronous spontaneous activity generated in hippocampal circuits. We used a method of statistical analysis that identifies and maps the coactivations among individual cells (Schwartz et al., 1998; Aguado et al., 2003). Spatiotemporal analysis of control slices showed that only a moderate percentage of neurons belonged to correlated networks (Fig. 2D,K), as described previously (Aguado et al., 2003). A representative correlation analysis of a control embryo is shown
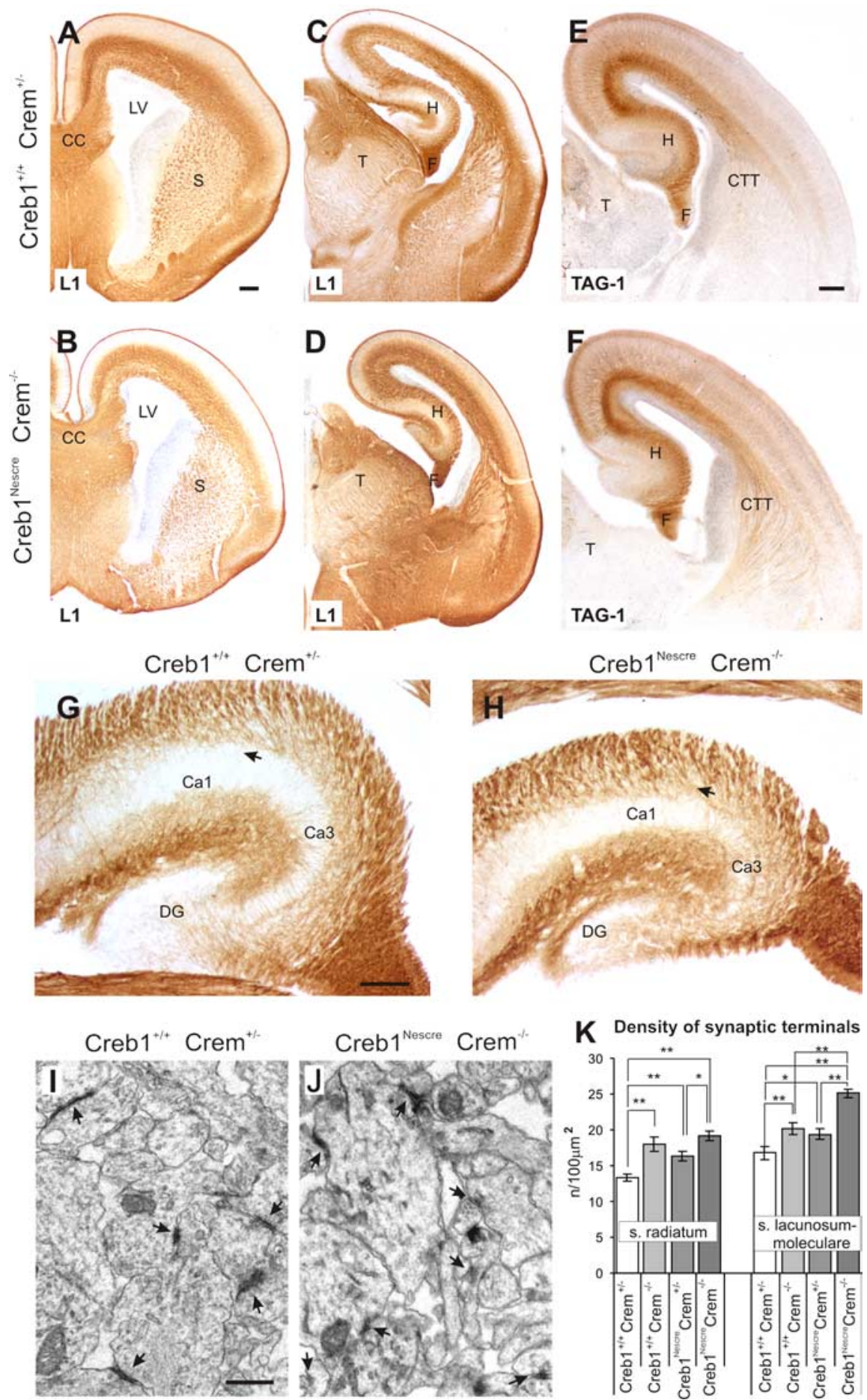

K Density of synaptic terminals

Figure 1. CREB/CREM mutant mice display normal fiber cytoarchitectonics but increased synaptogenesis. $\boldsymbol{A}-\boldsymbol{F}$, Coronal sections of E18 forebrains immunoreacted for L1 and TAG1 showing that the trajectories of the main fiber tracts of the forebrain are unaltered in CREB1 $^{\text {Nescre }}{ }^{2}$ EM ${ }^{-/-}$embryos. CC, Corpus callosum; CTT, corticothalamic tract; F, fimbria; H, hippocampus; S, striatum; T, thalamus. G-H, Hippocampal sections immunoreacted for $\mathrm{L} 1$ showing similar patterns of fiber distribution (arrows) in $\mathrm{CREB} 1{ }^{+/+} \mathrm{CREM}^{+/-}$and CREB1 $^{\text {Nescre }}{ }^{\text {CREM }}{ }^{-/-}$embryos. DG, Dentate gyrus; CA1-CA3, hippocampal subfields. I,J, Electron micrographs showing axon terminals displaying synaptic contacts (arrows) in the stratum radiatum of CREB1 ${ }^{+/+}$CREM $^{+/-}$and CREB1 ${ }^{\text {Nescre }}$ CREM $^{-/-}$hippocampi. $\boldsymbol{K}$, Density of synaptic terminals in the stratum radiatum and stratum lacunosum moleculare in the genotypes showing increased number of contacts in CREB $1^{+/+} \mathrm{CREM}^{-/-}, \mathrm{CREB}^{\text {Nescre }} \mathrm{CREM}^{+/-}$, and CREB $1^{\text {Nescre }} \mathrm{CREM}^{-/-}$embryos, compared with CREB $1^{+/+} \mathrm{CREM}^{+/-}$ brains. $\left.{ }^{*} p<0.05,{ }^{* *} p<0.01\right)$. Scale bars: $\boldsymbol{A}-\boldsymbol{H}, 200 \mu \mathrm{m} ; \boldsymbol{I}, \boldsymbol{J}, 0.5 \mu \mathrm{m}$. in Figure $2 F$, where each fura-2-loaded pyramidal neuron displaying spontaneous $\left[\mathrm{Ca}^{2+}\right]_{\mathrm{i}}$ changes is indicated with black squares and the spatiotemporal correlation map (see Materials and Methods) shows the synchronous network shaped by coac- 

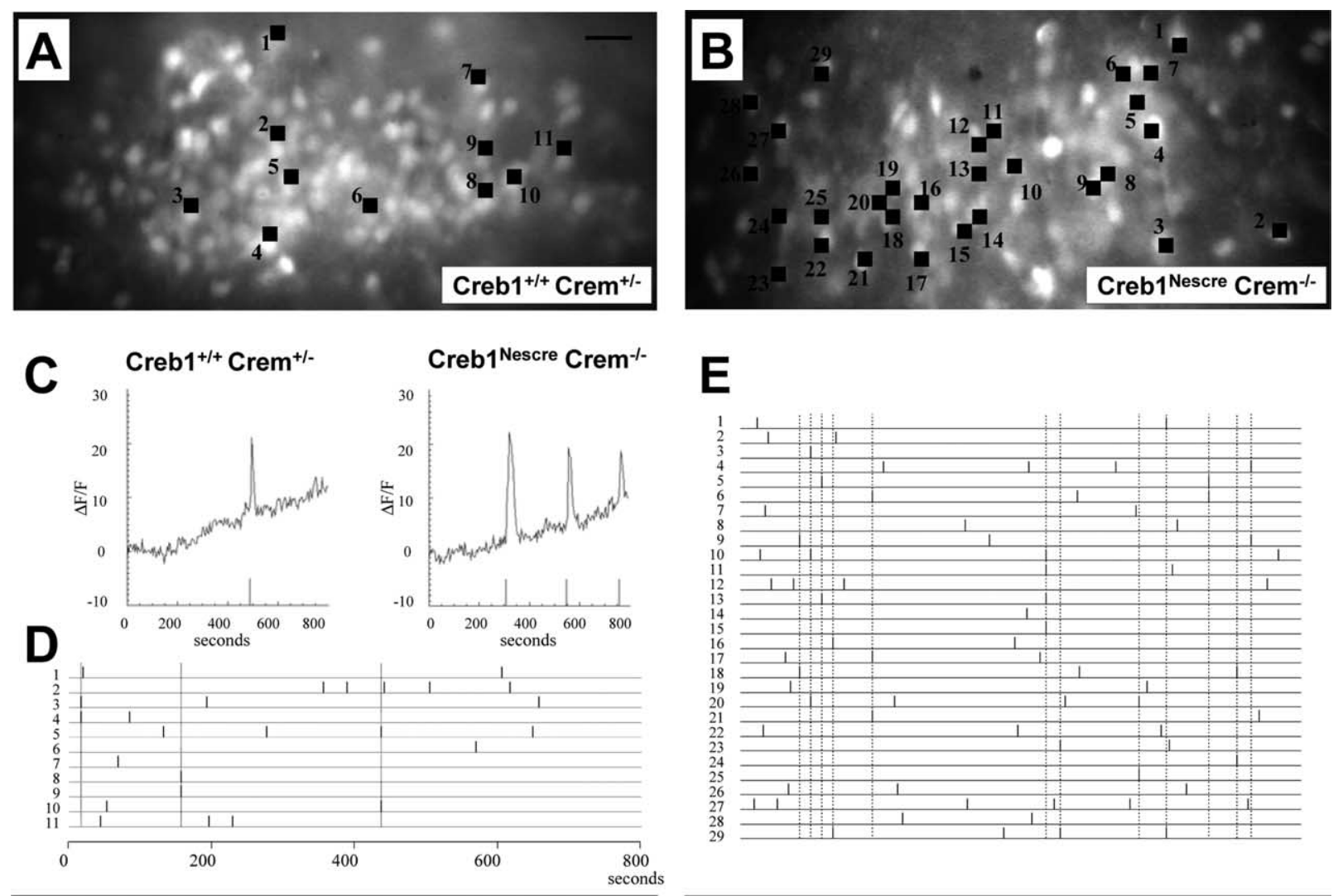

E
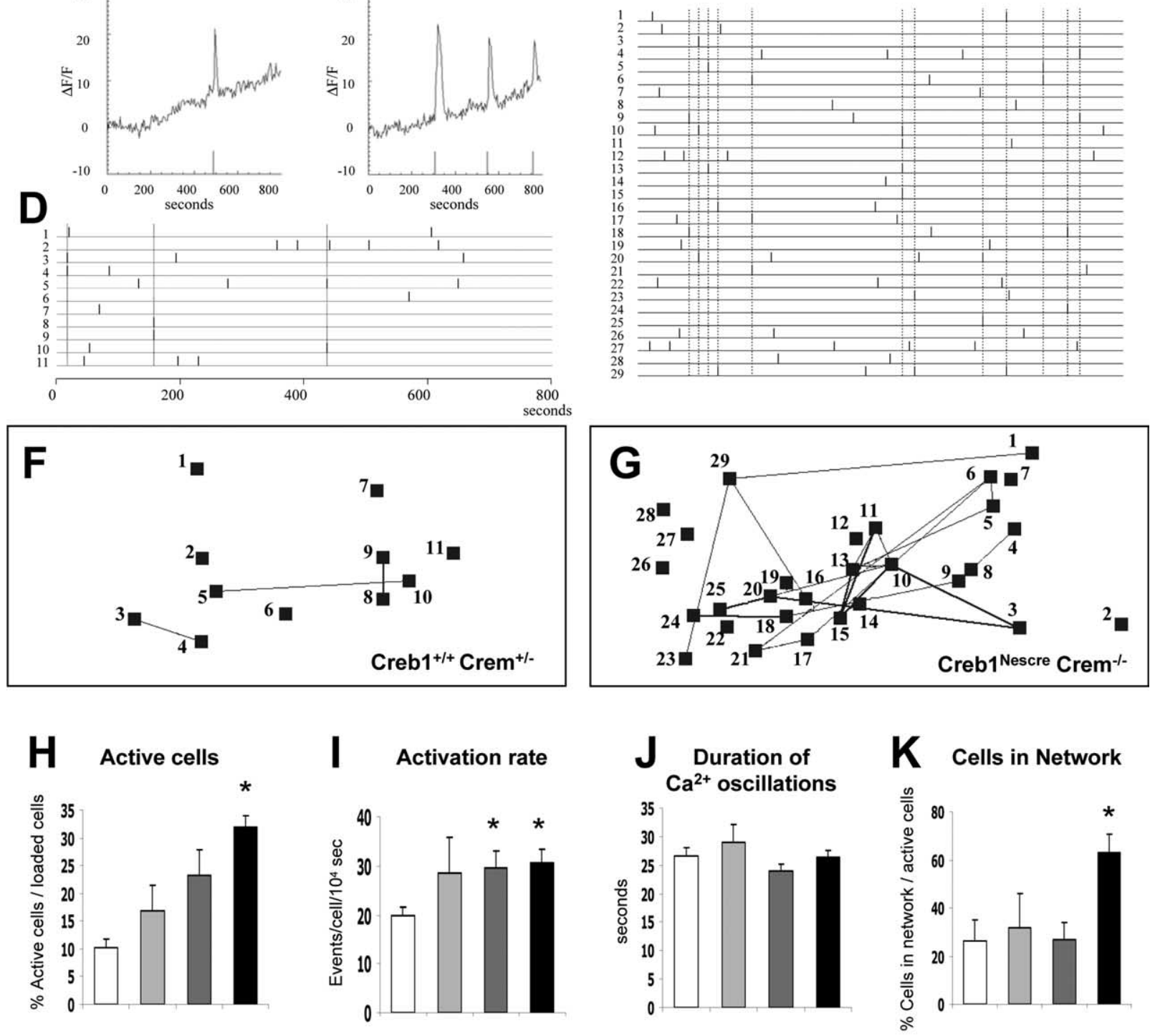

\section{$\square \mathrm{Creb1}^{+/+} \mathrm{Crem}^{+/-} \square \mathrm{Creb1}^{\mathrm{Nescre}} \mathrm{Crem}^{-/-} \square \mathrm{Creb1}^{+/+} \mathrm{Crem}^{-/-} \quad \square$ Creb1 $^{\mathrm{Nescre}} \mathrm{Crem}^{+/-}$}

Figure 2. Spontaneous correlated network activity is enhanced in the hippocampus of E18 $C R E B 1^{\text {Nescre }} C R E M^{+/-}$and CREB $1^{\text {Nescre }} C R E M^{-/-}$embryos. $A-G$, Examples of network activity in the hippocampal CA1 region of CREB1 ${ }^{+/+}$CREM $^{+/-}$and CREB $1^{\text {Nescre }}$ CREM ${ }^{-/-}$embryos. $A, B$, Fura-2-loaded hippocampal slices showing active neurons (squares). $C$, Representative plots of $\Delta F / F$ over time illustrating spontaneous $\left[\mathrm{Ca}^{+2}\right]_{\mathrm{i}}$ changes in a hippocampal neuron. The initiation of $\left[\mathrm{Ca}^{+2}\right]_{\mathrm{i}}$ transients is indicted by bars on the $x$-axis. $\boldsymbol{D}, \boldsymbol{E}$, Raster plots of all active cells shown in $\boldsymbol{A}$ and $B$ in a CREB1 ${ }^{+/+}$CREM $^{+/-}(\boldsymbol{D})$ and $C R E B 1^{\text {Nescre }}$ RREM $^{-/-}(\boldsymbol{E})$ slice. Horizontal lines represent the activity profile over $800 \mathrm{~s}$ of each active neuron, and vertical thick lines mark the onset of $\left[C a^{+2}\right]_{\mathrm{i}}$ oscillations. The long vertical lines crossing the horizontal lines in $\boldsymbol{D}$ and $\boldsymbol{E}$ mark the times where the onset of the oscillations is synchronous across multiple cells. $\boldsymbol{F}, \boldsymbol{G}$, Correlation maps illustrating a significant $\left(p<0.01\right.$ ) spatiotemporal coactivation among all cell pairs shown in $\boldsymbol{A}-\boldsymbol{D}$ and $\boldsymbol{B}-\boldsymbol{E}$ assayed with $\chi^{2}$ contingency tables. Each pair of synchronous cells is connected by lines. The thickness of the lines is proportional to the degree of significance. The $p$ value reflects the overall level of coactivation obtained by Monte Carlo simulation and represents the probability that the coactivations present in this field are caused by chance. The complexity of spatiotemporal correlations is enhanced in CREB $1^{\text {Nescre } C R E M}{ }^{-1-}$ embryos, as denoted by the increased number of cells involved in correlated networks. $\boldsymbol{H}-\boldsymbol{K}$, Histograms showing significant increases in the percentage of active neurons $(\boldsymbol{H})$, the activation rates $\mathrm{Ca}^{2+}$ transients/cell/10 ${ }^{4} \mathrm{~s}(\boldsymbol{I})$, and the number of active cells involved in correlated networks in CREB1 ${ }^{\text {Nescre }}$ CREM ${ }^{-1-}$ hippocampal slices $(\boldsymbol{K})$, whereas durations of $\mathrm{Ca}^{2+}$ oscillation do not differ $(\boldsymbol{J}) .{ }^{*} p<0.01$. Scale bar, $50 \mu \mathrm{m}$. 
tive neurons. In these correlation maps, each pair of neurons with significant synchronous $\left[\mathrm{Ca}^{2+}\right]_{\mathrm{i}}$ increases is connected by lines whose thickness is proportional to the degree of correlation. Analysis of patterned spontaneous activity of CREB ${ }^{\text {Nescre }} \mathrm{CREM}^{-/-}$littermates revealed that double mutants had an average of $62.9 \pm 7.8 \%$ of coactivated neurons, $2.4 \times$ more than in controls (Fig. $2 E, K$ ). Moreover, no changes were observed in the percentage of neurons showing synchronous $\mathrm{Ca}^{2+}$ events in single mutants (Fig. $2 K$ ). We conclude that the elimination of CREB and CREM genes in vivo markedly enhances spontaneous neuronal activity in the prenatal brain by increasing the number of active neurons and activation rates and their patterns of synchronized activity.

To study the cellular mechanisms underlying nonevoked $\mathrm{Ca}^{2+}$ events in control and CREB $1{ }^{\text {Nescre }} \mathrm{CREM}^{-1-}$ mutant embryos, we used a pharmacological approach. Rapid removal of extracellular $\mathrm{Ca}^{2+}$ by perfusion with $\mathrm{Ca}^{2+}$-free ACSF containing $2 \mathrm{~mm}$ EGTA completely blocked spontaneous $\left[\mathrm{Ca}^{2+}\right]_{\mathrm{i}}$ oscillations in both controls and CREB ${ }^{\text {Nescre }}{ }^{\text {CREM }}{ }^{-/-}$neurons (three and two slices, respectively) (Fig. $3 A$ ). We also analyzed the contribution of released intracellular $\mathrm{Ca}^{2+}$ to spontaneous $\left[\mathrm{Ca}^{2+}\right]_{\mathrm{i}}$ transients by applying thapsigargin, which depletes intracellular $\mathrm{Ca}^{2+}$ stores. Addition of thapsigargin $(2 \mu \mathrm{M})$ to hippocampal slices did not alter the percentage of neurons with spontaneous $\left[\mathrm{Ca}^{+2}\right]_{\mathrm{i}}$ transients in control or CREB1 ${ }^{\text {Nescre }} \mathrm{CREM}^{-/-}$embryos (two and two slices, respectively) (Fig. $3 A$ ). These results indicate that neuronal $\left[\mathrm{Ca}^{+2}\right]_{\mathrm{i}}$ oscillations depend almost exclusively on extracellular $\mathrm{Ca}^{2+}$ and that the mechanisms underlying $\mathrm{Ca}^{2+}$ mobilization are preserved in CREB $1{ }^{\text {Nescre }} \mathrm{CREM}^{-1-}$ double mutants. Administration of the $\mathrm{GABA}_{\mathrm{A}}$ receptor antagonist $\mathrm{BMI}$ $(30 \mu \mathrm{M})$ to control hippocampal slices reduced the number of spontaneously active cells (42.5\%, two slices). Similar blocking effects were observed in embryonic neurons of CREB $1{ }^{\text {Nescre }}$ CREM $^{-/-}$slices after treatment with BMI $(48.8 \%$ active neurons, three slices) (Fig. 3A). Moreover, blockade of ionotropic glutamate receptors by APV and CNQX (50 and 20 $\mu \mathrm{M}$, respectively) showed that the activation of these receptors contributed similarly to the generation of intrinsic activity in embryonic neurons of control and CREB $1^{\text {Nescre }}{ }^{\text {CREM }}{ }^{-/-}$hippocampi (Fig. 3A). These observations were supported by a rise in the Monte Carlo $p$ value (Fig. $3 B$ ), which reflects the overall network decorrelation (Schwartz et al., 1998). We also analyzed protein expression levels of several subunit neurotransmitter receptors, including $\mathrm{GABA}_{\mathrm{A}} \alpha 1$, NMDAR1, and GluR2/3. In agreement with the above data, no differences in the expression levels of these subunits between control and CREB $1^{\text {Nescre }}{ }^{\mathrm{CREM}}{ }^{-1-}$ mutant embryos were detected (Fig. 3C).

\section{Discussion}

These results are consistent with previous reports showing that the excitatory actions of both GABA and glutamate are required for the generation of spontaneous activity in the hippocampus
(Leinekugel et al., 1997; Garaschuk et al., 1998, 2000; Aguado et al., 2003). Moreover, our findings indicate that the elimination of the CREB and CREM genes does not substantially alter the physiological contribution of the main ionotropic receptors to generate spontaneous $\mathrm{Ca}^{2+}$ activity. This suggests that the increased level of neural activity observed in CREB ${ }^{\text {Nescre }} \mathrm{CREM}^{-/-} \mathrm{mu}-$ tant embryos is attributable to the dramatic increase in synaptogenesis. Previous studies have shown that the lack of CREB and CREM genes results in an increased number of degenerating neurons (Mantamadiotis et al., 2002). Whether this process is related to the altered patterns of connectivity and neural activity described in the present study remains to be elucidated.

The development of neural connections follows two essentially independent processes: initially, growing fibers are guided toward their targets and form early synapses in an activityindependent manner; then, activity-dependent axonal branching and synaptogenesis occur (Katz and Shatz, 1996; Tessier-Lavigne and Goodman, 1996). The role of the CREB family of transcription factors in activity-dependent plasticity processes, including LTP, long-term memory, and formation and stabilization of new synapses, in the postnatal and adult brain, is well established (Murphy and Segal, 1997; Gass et al., 1998; Mayr and Montminy, 2001; Barco et al., 2002; Lonze et al., 2002; Pittenger et al., 2002; Gao et al., 2004; Marie et al., 2005). In contrast, little is known about the role of the CREB transcription factors in axonal growth and guidance, or in the early patterns of neural activity in the precritical period. A reduction in the size of some axonal pathways, including the corpus callosum, has been found in conventional CREB null mutant embryos (Rudolph et al., 1998). In CREB $1{ }^{\text {Nescre }}$ CREM $^{-/-}$mutants, we did not detect either aberrant axonal tracts or reduced axonal pathways in distinct regions of the CNS. These differences may be attributable to the fact that we used Cre/loxP mutants in which the CREB gene is targeted 
exclusively in neural and glial progenitors at the onset of Nestin expression (Mantamadiotis et al., 2002). Thus, the reduced sizes of axonal tracts in germline CREB mutants (Rudolph et al., 1998) may be secondary to CREB-dependent processes occurring at earlier embryonic stages (Bleckmann et al., 2002).

We show here a marked increase in the number of synapses in the hippocampus of CREB $1^{\text {Nescre }} \mathrm{CREM}^{-/-}$embryos. Consistently, the patterns of spontaneous intrinsic activity in doublemutant hippocampi showed a marked increase in the number of activated neurons and also in their synchronous network activity. Interestingly, the analysis of the neural activity in pyramidal cells reveals enhanced activity in the single and double mutants, lacking only CREB or both CREB and CREM genes. The finding that spontaneous activity in CREB/CREM mutants is reduced after treatment with neurotransmitter receptor antagonists indicates that the enhanced spontaneous activity observed is attributable, at least in part, to the increased number of synaptic contacts in these mutants. Moreover, GABAergic and glutamatergic receptor antagonists reduced activity by only $60 \%$; it is likely that other neurotransmitter systems or mechanisms (e.g., gap junctions) collaborate in driving this activity. It has been shown that the frequency of patterned neural activity drives the refinement and segregation of initially imprecise connections (Stellwagen and Shatz, 2002; Hanson and Landmesser, 2004; Torborg et al., 2005; Demas et al., 2006). Our results therefore agree with these findings by demonstrating a correlation between altered patterns of neural activity patterns and abnormal synaptogenesis.

In summary, we show that the lack of CREB/CREM genes in neural tissue leads to increased synaptogenesis and spontaneous neural network activity specifically at early developmental stages, in contrast to the critical period and adult brain, where they are required for neural activity-dependent synaptogenesis, refinement, and plasticity. These data point to an unexpected role of the CREB/CREM genes in neural development and suggest that unidentified age-dependent factors modulate the activity of CREB/ CREM genes and their transcriptional activity in the same neurons. Such differential regulation might be achieved by a differential expression of signaling pathways controlling CREB/ CREM phosphorylation and/or by inhibition of transcription induced by these genes.

\section{References}

Aguado F, Carmona MA, Pozas E, Aguiló A, Martínez-Guijarro FJ, Alcantara S, Borrell V, Yuste R, Ibañez CF, Soriano E (2003) BDNF regulates spontaneous correlated activity at early developmental stages by increasing synaptogenesis and expression of the $\mathrm{K}+/ \mathrm{Cl}$ - co-transporter KCC2. Development 130:1267-1280.

Barco A, Alarcon JM, Kandel ER (2002) Expression of constitutively active CREB protein facilitates the late phase of long-term potentiation by enhancing synaptic capture. Cell 108:689-703.

Ben-Ari Y (2001) Developing networks play a similar melody. Trends Neurosci 24:353-360.

Bleckmann SC, Blendy JA, Rudolph D, Monaghan AP, Schmid W, Schütz G (2002) Activating transcription factor 1 and CREB are important for cell survival during early mouse development. Mol Cell Biol 22:1919-1925.

Demas J, Sagdullaev BT, Green E, Jaubert-Miazza L, McCall MA, Gregg RG, Wong RO, Guido W (2006) Failure to maintain eye-specific segregation in nob, a mutant with abnormally patterned retinal activity. Neuron 50:247-259.
Feller MB, Scanziani M (2005) A precritical period for plasticity in visual cortex. Curr Opin Neurobiol 15:94-100.

Gao Y, Deng K, Hou J, Bryson JB, Barco A, Nikulina E, Spencer T, Mellado W, Kandel ER, Filbin MT (2004) Activated CREB is sufficient to overcome inhibitors in myelin and promote spinal axon regeneration in vivo. Neuron 44:609-621.

Garaschuk O, Hanse E, Konnerth A (1998) Developmental profile and synaptic origin of early network oscillations in the CA1 region of rat neonatal hippocampus. J Physiol 507:219-236.

Garaschuk O, Linn J, Eilers J, Konnerth A (2000) Large-scale oscillatory calcium waves in the immature cortex. Nat Neurosci 3:452-459.

Gass P, Wolfer DP, Balschun D, Rudolph D, Frey U, Lipp HP, Schütz G (1998) Deficits in memory tasks of mice with CREB mutations depend on gene dosage. Learn Mem 5:274-288.

Hanson MG, Landmesser LT (2004) Normal patterns of spontaneous activity are required for correct motor axon guidance and the expression of specific guidance molecules. Neuron 43:687-701.

Hensch TK (2005) Critical period plasticity in local cortical circuits. Nat Rev Neurosci 6:877-888.

Hooks BM, Chen C (2006) Distinct roles for spontaneous and visual activity in remodeling of the retinogeniculate synapse. Neuron 52:281-291.

Huberman AD, Speer CM, Chapman B (2006) Spontaneous retinal activity mediates development of ocular dominance columns and binocular receptive fields in V1. Neuron 52:247-254.

Katz LC, Shatz CJ (1996) Synaptic activity and the construction of cortical circuits. Science 274:1133-1138.

Leinekugel X, Medina I, Khalilov I, Ben-Ari Y, Khazipov R (1997) $\mathrm{Ca}^{2+}$ oscillations mediated by the synergistic excitatory actions of $\mathrm{GABA}_{(\mathrm{A})}$ and NMDA receptors in the neonatal hippocampus. Neuron 18:243-255.

Lonze BE, Riccio A, Cohen S, Ginty DD (2002) Apoptosis, axonal growth defects, and degeneration of peripheral neurons in mice lacking CREB. Neuron 34:371-385.

Mantamadiotis T, Lemberger T, Bleckmann SC, Kern H, Kretz O, Martin Villalba A, Tronche F, Kellendonk C, Gau D, Kapfhammer J, Otto C, Schmid W, Schütz G (2002) Disruption of CREB function in brain leads to neurodegeneration. Nat Genet 31:47-54.

Marie H, Morishita W, Yu X, Calakos N, Malenka RC (2005) Generation of silent synapses by acute in vivo expression of CaMKIV and CREB. Neuron 45:741-752.

Mayr B, Montminy M (2001) Transcriptional regulation by the phosphorylation-dependent factor CREB. Nat Rev Mol Cell Biol 2:599-609.

Murphy DD, Segal M (1997) Morphological plasticity of dendritic spines in central neurons is mediated by activation of cAMP response element binding protein. Proc Natl Acad Sci U S A 94:1482-1487.

Pittenger C, Huang YY, Paletzki RF, Bourtchouladze R, Scanlin H, Vronskaya S, Kandel ER (2002) Reversible inhibition of CREB/ATF transcription factors in region CA1 of the dorsal hippocampus disrupts hippocampusdependent spatial memory. Neuron 34:447-462.

Rudolph D, Tafuri A, Gass P, Hämmerling GJ, Arnold B, Schütz G (1998) Impaired fetal $\mathrm{T}$ cell development and perinatal lethality in mice lacking the cAMP response element binding protein. Proc Natl Acad Sci U S A 95:4481-4486.

Schwartz TH, Rabinowitz D, Unni V, Kumar VS, Smetters DK, Tsiola A, Yuste R (1998) Networks of coactive neurons in developing layer 1. Neuron 20:541-552.

Spitzer NC (2006) Electrical activity in early neuronal development. Nature 444:707-712.

Stellwagen D, Shatz CJ (2002) An instructive role for retinal waves in the development of retinogeniculate connectivity. Neuron 33:357-367.

Tessier-Lavigne M, Goodman CS (1996) The molecular biology of axon guidance. Science 274:1123-1133.

Torborg CL, Hansen KA, Feller MB (2005) High frequency, synchronized bursting drives eye-specific segregation of retinogeniculate projections. Nat Neurosci 8:72-78. 